\title{
Author Correction: Intracellular localization of nanoparticle dimers by chirality reversal
}

\author{
Maozhong Sun ${ }^{1,2}$, Liguang Xu'1,2, Joong Hwan Bahng ${ }^{3,4}$, Hua Kuang ${ }^{1,2}$, Silas Alben ${ }^{5}$, Nicholas A. Kotov (1) 3,4,6,7,8 \\ $\&$ Chuanlai Xu (iD) 1,2
}

Correction to: Nature Communications https://doi.org/10.1038/s41467-017-01337-2; published online 29 Nov 2017

The original version of this Article contained an error in the spelling of the author Joong Hwan Bahng, which was incorrectly given as Joong Hwan Banhg. This has been corrected in both the PDF and HTML versions of the Article.

Published online: 27 August 2018

\begin{abstract}
cc) reproduction in any medium or format, as long as you give appropriate credit to the original author(s) and the source, provide a link to the Creative Commons license, and indicate if changes were made. The images or other third party material in this article are included in the article's Creative Commons license, unless indicated otherwise in a credit line to the material. If material is not included in the article's Creative Commons license and your intended use is not permitted by statutory regulation or exceeds the permitted use, you will need to obtain permission directly from the copyright holder. To view a copy of this license, visit http://creativecommons.org/licenses/by/4.0/.
\end{abstract}

(C) The Author(s) 2018

\footnotetext{
${ }^{1}$ State Key Laboratory of Food Science and Technology, Jiangnan University, Wuxi 214122, China. ${ }^{2}$ International Joint Research Laboratory for Biointerface and Biodetection, Jiangnan University, Wuxi 214122, China. ${ }^{3}$ Chemical Engineering Department, University of Michigan, Ann Arbor, MI 48109, USA.

${ }^{4}$ Department of Biomedical Engineering, University of Michigan, Ann Arbor, MI 48109, USA. ${ }^{5}$ Department of Mathematics, University of Michigan, Ann Arbor, MI 48109, USA. ${ }^{6}$ Department of Material Sciences and Engineering, University of Michigan, Ann Arbor, MI 48109, USA. ${ }^{7}$ Michigan Center for Integrative Research in Critical Care, Ann Arbor, MI 48109, USA. ${ }^{8}$ Biointerfaces Institute, University of Michigan, Ann Arbor, MI 48109, USA. These authors contributed equally: Maozhong Sun, Liguang Xu. Correspondence and requests for materials should be addressed to H.K. (email: kuangh@jiangnan.edu.cn) or to N.A.K. (email: kotov@umich.edu)
} 